\title{
Expression of zebrafish aldh1a3 (raldh3) and absence of aldhlal in teleosts
}

\author{
Silke Pittlik, Susana Domingues, Axel Meyer, Gerrit Begemann * \\ Chair for Zoology \& Evolutionary Biology, Department of Biology, University of Konstanz, Fach M617, 78457 Konstanz, Germany
}

\begin{abstract}
The vitamin A derived morphogen retinoic acid (RA) plays important roles during the development of chordate animals. The Aldh1a family of RA synthesizing enzymes consists of three members, Aldh1a1 3 (Raldh1 3), that are dynamically expressed throughout devel opment. We have searched the known teleost genomes for the presence of Raldh family members and have found that teleost fish possess orthologs of Aldh1a2 and Aldh1a3 only. Here we describe the expression of aldhla3 in the zebrafish, Danio rerio. Whole mount in situ hybridization shows that aldhla3 is expressed during eye development in the retina flanking the optic stalks and later is expressed ven trally, opposite the expression domain of aldhla2. During inner ear morphogenesis, aldhla3 is expressed in developing sensory epithelia of the cristae and utricular macula and is specifically up regulated in epithelial projections throughout the formation of the walls of the semicircular canals and endolymphatic duct. In contrast to the mouse inner ear, which expresses all three Raldhs, we find that only aldhla3 is expressed in the zebrafish otocyst, while aldhla2 is present in the periotic mesenchyme. During larval stages, additional expres sion domains of aldhla3 appear in the anterior pituitary and the swim bladder. Our analyses provide a starting point for genetic studies to examine the role of RA in these organs and emphasize the suitability of the zebrafish inner ear in dissecting the contribution of RA signaling to the development of the vestibular system.
\end{abstract}

Keywords: Retinoic acid; RA synthesis; Raldh1; Raldh2; Raldh3; Zebrafish; Ear development; Otic vesicle; Semicircular canal; Crista; Utricular macula; Endolymphatic duct; Retina; Pituitary; Swim bladder; Adenohypophysis

\section{Results and discussion}

All-trans retinoic acid (RA), the major biologically active metabolite of vitamin $\mathrm{A}$, acts as a signal to regulate gene expression by controlling the activity of members of the RA-regulated nuclear receptor family, the RA receptors (RARs) and the retinoid $\mathrm{X}$ receptors (RXRs) (reviewed in: Begemann and Meyer, 2001). RA biosynthesis involves a two-step process, in which the precursor vitamin A (retinol) is first oxidized by cytosolic alcohol dehydrogenases to retinaldehyde. In a second step, retinaldehyde is converted to RA by cytosolic retinal dehydrogen-

\footnotetext{
* Corresponding author. Tel.: +49 7531 882881; fax: +49 7531883018. E mail address: gerrit.begemann@uni konstanz.de (G. Begemann).
}

ases, which are members of the aldehyde dehydrogenase $(\mathrm{ALDH})$ family. In vertebrates, three enzymes have been described, Aldh1a1 3 (formerly called Raldh1 3) (Duester, 2000; Sophos and Vasiliou, 2003), that are highly specific for the synthesis of RA and are expressed in tissues with a high retinoid content (Niederreither et al., 1997; Berggren et al., 1999; Haselbeck et al., 1999; Li et al., 2000; Begemann et al., 2001; Chen et al., 2001). Of these, Aldh1a3 has been identified and its developmental roles have been partially resolved in Xenopus laevis, the chick (Aldh6) and mouse (Raldh3) (Grün et al., 2000; Li et al., 2000; Mic et al., 2000; Suzuki et al., 2000; Lupo et al., 2005). A recent survey of the Aldhla-gene family in deuterostomes demonstrated that zebrafish, in addition to the well-characterized aldh1a2 gene, possess aldhla3, but lack aldhlal (Canestro et al., 2006). Here we show that the lack of aldhlal is a general 
trait of teleosts and describe the embryonic and early larval expression patterns of zebrafish aldhla3.

\subsection{Phylogeny analysis of teleost retinaldehyde dehydrogenases}

We have amplified a fragment spanning three exons of a novel retinaldehyde dehydrogenase (Raldh), present in $24 \mathrm{~h}$ post-fertilization (hpf) zebrafish embryos, that we identified by homology screening with sequences of known vertebrate Raldhs among genomic sequences published in Ensembl (Hubbard et al., 2007). During the course of this work, an expressed sequence tag covering the full open reading frame of this gene had become available in GenBank and was provisionally named aldhla3. To determine the presence of Raldhs in teleosts other than the zebrafish, we identified all genes from the close to complete pufferfish (Takifugu rubripes, Tetraodon nigrovirides) and stickleback (Gasterosteus aculeatus) genomes that exhibit significant sequence similarities to Aldh1a1 3. A phylogeny analysis of the encoded proteins, including the known human, mouse, chicken and Xenopus sequences, assigned the identified sequences to three branches representing the Raldhfamily members Aldh1a1 (Raldh1), Aldh1a2 (Raldh2) and Aldh1a3 (Raldh3), respectively (Sophos and Vasiliou, 2003), and identify the second zebrafish Raldh as Aldh1a3 (Fig. 1). We note that members of the Aldh1a1 gene family are neither present in the fish species sampled, nor did we succeed in identifying Aldhlal genes among any other publicly available fish sequences (Table 1), suggesting that teleosts in general only possess Aldh1a2 and Aldh1a3. Zebrafish aldhla3 is located on chromosome 7 (mapping data were produced at the Sanger Institute and were obtained from the World Wide Web at http://www.sanger.ac.uk), with a total of 13 exons extending over a length of 81,835 nucleotides (positions 8,113,850 8,195,685 in zebrafish assembly version 7; Ensembl release 46; August 2007). Zebrafish aldhla3 is therefore positioned $478 \mathrm{Mb}$ away from aldhla2 on the same chromosome, which corresponds to the localization of the human orthologous genes Aldhla2 and Aldhla3 in Hsa15q22.1 and Hsa15q26.3, respectively

Table 1

Accession numbers of Aldh1a gene family members in teleosts

\begin{tabular}{ll}
\hline Species & Gene accession \\
\hline Zebrafish (Danio rerio) & aldh1a2: AF315691 \\
& aldh1a3: DQ300198 \\
Stickleback (Gasterosteus aculeatus) & aldh1a2: \\
& ENSGACG00000015825 ${ }^{1)}$ \\
& aldh1a3: \\
& ENSGACG0000013986 \\
& aldh1a2: DQ897366 \\
Japanese Medaka (Oryzias latipes) & aldh1a2: CAAE01013867 \\
Spotted green pufferfish (Tetraodon & aldh1a3: CAAE01014118 \\
nigroviridis) & aldh1a2: NM 001033639 \\
Torafugu (Takifugu rubripes) & aldh1a3: \\
& NEWSINFRUG00000146554
\end{tabular}

Accession numbers retrieved from GenBank and: 1) ENSEMBL, Assem bly Broad S1 (Feb 2006); 2) ENSEMBL, Assembly HdrR (Oct 2005); 3) Assembly FUGU 4.0, Jun 2005.

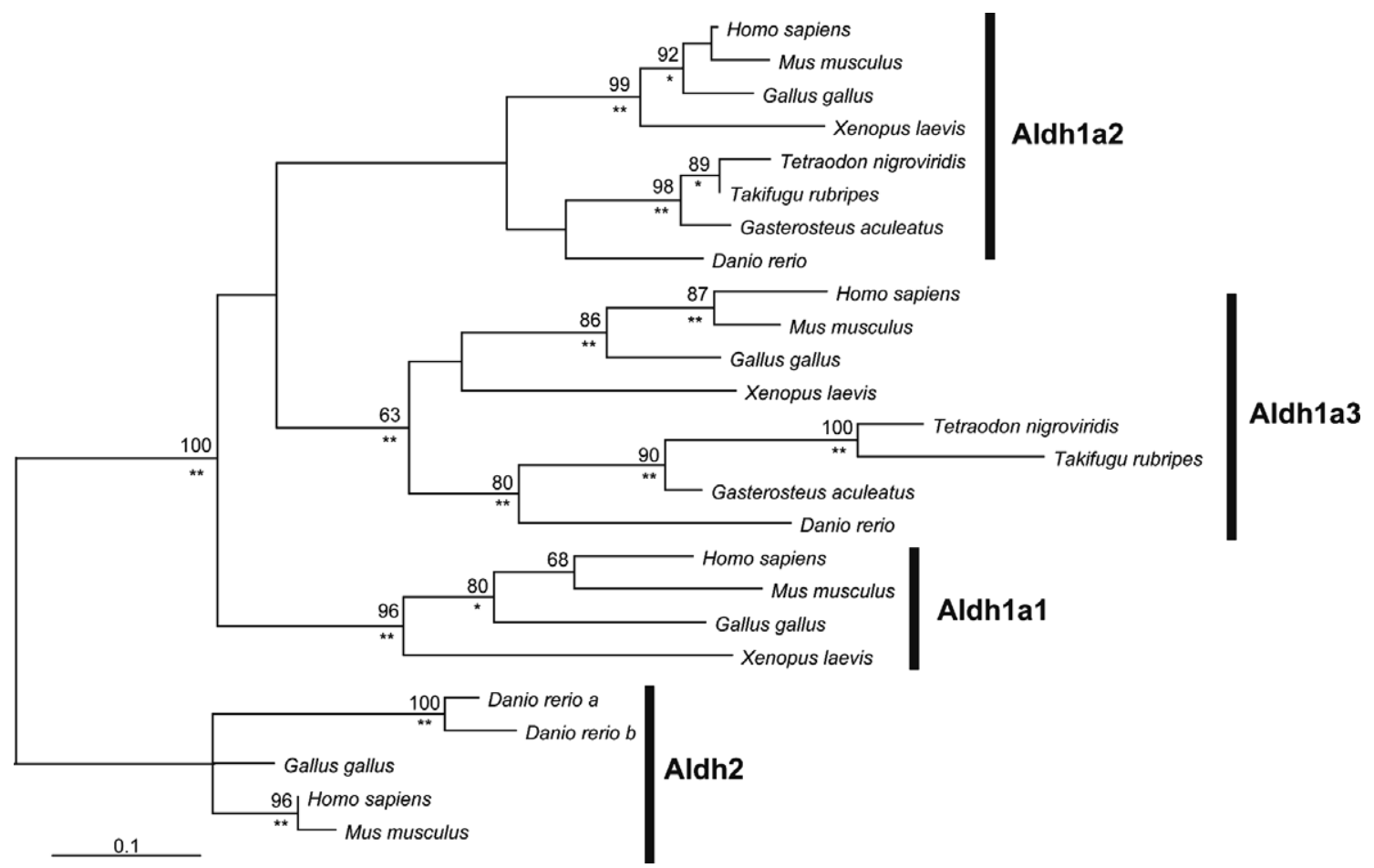

Fig. 1. Maximum likelihood tree of the Aldhla gene family using PHYML. Numbers represent bootstrap values supporting each node, values lower than 60 are not shown. Posterior probabilities as obtained by MrBayes 3.1.1 are indicated by asterisks $\left({ }^{* *} 100 \%\right.$, $\left.{ }^{*} 9599 \%\right)$. The tree was rooted using closely related sequences of the Aldh2 gene family. 
(Canestro et al., 2006). This, together with the clustering of vertebrate aldhla3 orthologs in the same branch of the phylogenetic tree (Fig. 1A) suggests that the common ancestor of mammals and teleosts already possessed both genes.

\subsection{Zebrafish aldhla3 is expressed in a non-overlapping pattern with aldh1a2 in the retina}

aldhla3 is first expressed in a single domain of the optic primordia covering all but the posterior-most third of the developing eye at $12 \mathrm{hpf}$ (not shown). This expression domain splits into similar sized dorsal and ventral halves by $16 \mathrm{hpf}$ that are located in the nasal part of the developing retina, adjacent to the diencephalon (Fig. 2A and B). Prior to the rotation of the eye, expression of aldhla3 becomes restricted to retinal tissue flanking the optic stalk by $20 \mathrm{hpf}$ (Fig. 2C). This expression domain becomes concentrated to neural epithelial cells on both sides of the choroid fissure by $48 \mathrm{hpf}$ (Fig. 2E and G). The expression domain ventral to the lens persists with little change throughout 4 days post-fertilization (Fig. $2 \mathrm{H}$ ). In comparison, at $20 \mathrm{hpf}$ aldhla2 is expressed opposite of aldhla3 in the posterior part of the retina (Fig. 2D) and after rotation of the eye will come to lie dorsal to the lens at $48 \mathrm{hpf}$ (Fig. 2F). Overall, the distribution of aldhla3 transcripts in the zebrafish eye are comparable to those in Xenopus (Lupo et al., 2005), chick (Adler and Belecky-Adams, 2002) and mouse (McCaffery et al., 1991; Li et al., 2000; Mic et al., 2000; Suzuki et al., 2000), where the gene is expressed in the ventral half of the retina. In the mouse, RA synthesized from Aldhla3, and in combination with Aldhlal and -a2, orchestrates the morphogenetic processes leading to eye development (Molotkov et al., 2006). In the absence of a dorsally expressed Aldhlal gene in zebrafish, aldh1a2 expression (Fig. 2D and F) may substitute as a dorsal source of RA.

\subsection{Expression of aldh1a3 in adenohypophysis and swim} bladder

aldhla3 expression was further detected in the midline of the upper jaw region, beginning around $72 \mathrm{hpf}$, and is clearly visible at $96 \mathrm{hpf}$ (Fig. 3A and C). A parallel staining for expression of pre-opiomelanocortin (pomca), a marker of corticotrope and melanotrope pituitary cell types at the anterior and posterior ends of the adenohypophysis (Fig. 3B) (Herzog et al., 2003), suggests that aldhla3 is co-expressed with pomca in the adenohypophysis. While pomca expression can already be detected in the stomodeal-hypophyseal placode prior to invagination (Herzog et al., 2003), aldhla3 expression is initiated considerably later in development and is absent from the more anterior pomca-expressing hypothalamic neurons (Fig. 3B). Expression of Raldhs has recently been demonstrated in the developing rat pituitary (Fujiwara et al., 2007). In addition to Raldh2, which is also expressed in the pituitary gland of the mouse (Niederreither et al., 1997), Raldh3 is expressed at high levels in Rathke's pouch and in its derivative, the anterior pituitary. Furthermore, we detect aldhla 3 expression in the swim bladder at $96 \mathrm{hpf}$, with strongest expression in its rostral part (Fig 3D and E). A transverse section at this level revealed that the gene is expressed in its epithelial lining (not shown).

\subsection{Dynamic changes of aldhla3 expression during morphogenesis of the developing inner ear}

The most dynamic expression pattern of aldhla3 was detected in the developing inner ear. aldhla 3 starts to be expressed in the anterior ventral otic epithelium between $20 \mathrm{hpf}$ (not shown) and $26 \mathrm{hpf}$, where it remains mainly unchanged until $36 \mathrm{hpf}$ (Fig. 4A). Weak expression of bmp4 and msxc marks the developing sensory epithelia of the cristae (Ekker et al., 1992; Mowbray et al., 2001), which
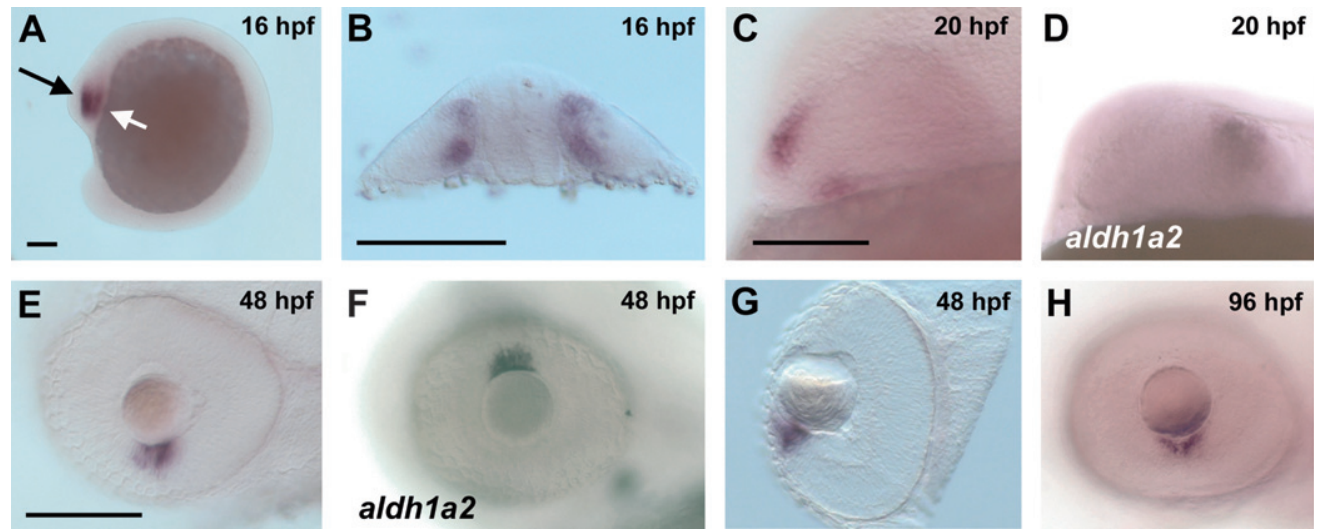

Fig. 2. Expression of aldhla3 in the developing eye. Expression of aldhla3 (A C, E, G, H) and aldhla2 (D and F) was detected by whole mount in situ hybridisation in the zebrafish eye. aldhla 3 was first detected in the eye primordium at $1216 \mathrm{hpf}$ (not shown; A, black arrow; B, transverse section through the plane indicated by the white arrow in A). While aldhla3 is expressed in a divided domain adjacent to the optic stalk at 20 hpf (C), aldhla2 is expressed in the temporal retina (D). From $36 \mathrm{hpf}$ to $48 \mathrm{hpf}$ aldhla 3 expression is visible in the retina ventral of the lens (E; G, transverse section through the eye). aldhla2 is expressed in the retina dorsal to the lens at $48 \mathrm{hpf}(\mathrm{F})$. At $96 \mathrm{hpf}$ aldhla 3 remains expressed in two domains in the retina ventral of the lens (H). All figures show the embryos in a lateral view, anterior to the left, unless indicated otherwise. Scale bars, $100 \mu \mathrm{m}$. 

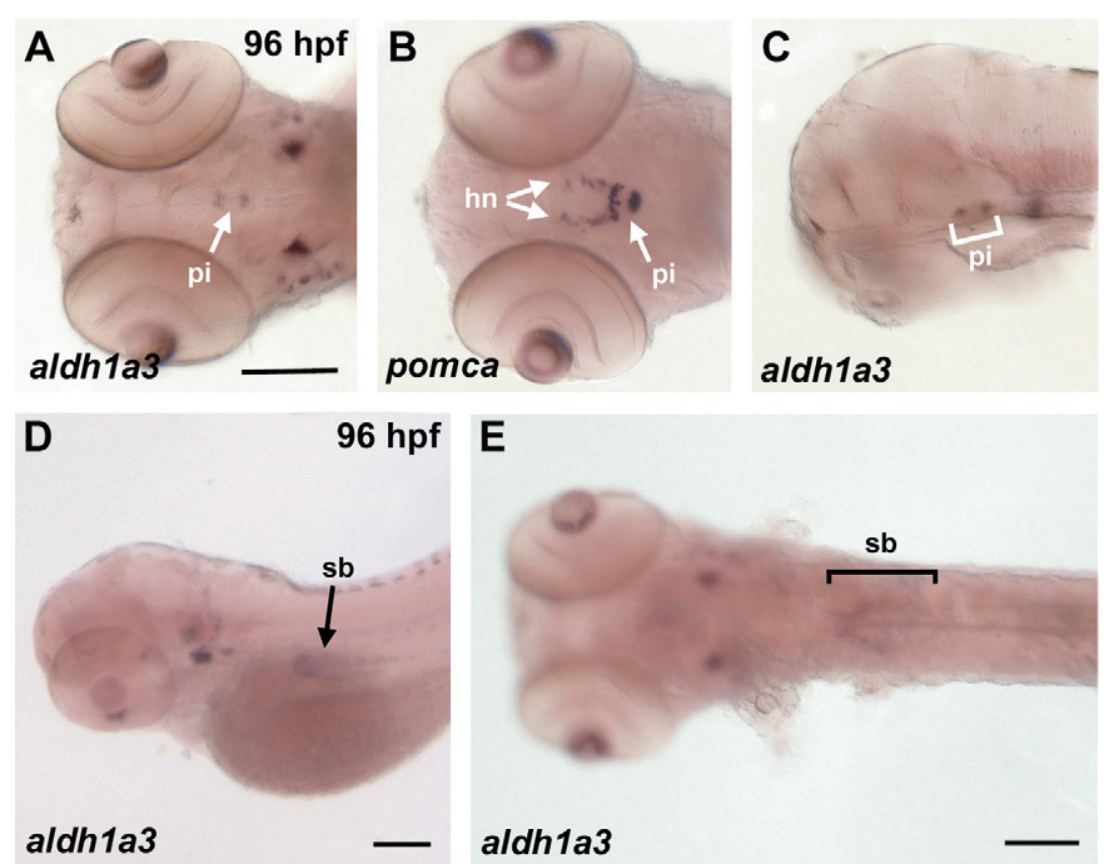

Fig. 3. aldh1a3 expression in adenohypophysis and swim bladder. Expression of aldh1a3 (A, C E) and pomca (B) was detected by whole mount in situ hybridisation in the zebrafish pituitary and swim bladder at $96 \mathrm{hpf}$. Comparison to pomca expression in the pituitary (pi) and the hypophyseal neurons (hn) (B, dorsal view) suggests that aldhla3 is expressed in anterior lobe of the hypophysis (A, dorsal view, C, mid sagittal section, anterior to the left). A further expression domain of aldhla3 exists in the swim bladder (sb) (D, lateral view; E, ventral view). Scale bars, $100 \mu \mathrm{m}$.

do not appear to overlap with aldhla3 expression at this stage (Fig. 4B and not shown). In view of its expression at later stages (see below), aldhla3 may therefore mark the sensory epithelium of the anterior macula, which develops earlier than the cristae and is located in this approximate position (reviewed in: Whitfield et al., 2002). At $48 \mathrm{hpf}$ aldh1a3 is strongly expressed in all cristae, in the epithelia of the dorsal wall of the otocyst (Fig. 4C, G and H), and in an anterior ventral region that by comparison to the expression of $i g f b p 3$ (Li et al., 2005), we identify as the anterior (utricular) macula (Fig. 4C and D). Interestingly, aldhla3 expression is spatially restricted to opposing sectors within the cristae (Fig. 4G), whereas bmp4 and msxc appear to be expressed throughout these epithelia (Fig. 4E and F). aldhla3 expression in the dorsal wall of the otocyst, which marks the appearance of endolymphatic duct, overlaps with that of bmp4 (Fig. 4C and E). Changes in the aldhla3 expression pattern start to become very dynamic after $48 \mathrm{hpf}$ and appear to follow the emergence of the epithelial projections that will form the walls of the semicircular canals. For example, at $50 \mathrm{hpf}$ two expression domains can be discerned in the cranial epithelial projection, which forms in a dorso-rostral position, on the lateral and medial surfaces of the projection, respectively (Fig. 4I). Other aldhla3-positive domains appear later in rostral and central positions, presumably prefiguring the caudal and lateral projections (not shown) (Waterman and Bell, 1984).

By $72 \mathrm{hpf}$ the walls that delimit the semicircular canals have fully formed and aldhla3 is not detected in these epithelia anymore; expression in the anterior macula is strong, as is expression in cells that form the growing endolymphatic duct (Fig. 4J). Expression in the cristae remains strong and, unlike for bmp4 and $m s x c$, is split into two regions lying opposite of each other at the borders of each crista (Fig. 4J and K), which becomes more prominent by $96 \mathrm{hpf}$ (Fig. 4L and M), while bmp4 and $m s x c$ expression is found throughout the cristae (Fig. $4 \mathrm{~N}$ and $\mathrm{O}$ ). In summary, aldhla3 expression in the non-sensory epithelia is highly dynamic, being strong during morphogenesis of the semicircular canals and endolymphatic duct, and fading once they are fully formed. It is of interest to note similarities as well as clear differences in patterns of RA synthesis during inner ear development between zebrafish and the mouse: Raldh 3 expression in the embryonic mouse inner ear, similar to the situation described here for the zebrafish, has been found in the lateral semicircular canal, in parts of the endolymphatic duct, as well as in the transitional epithelium of the cristae (Romand et al., 2004), which we interpret to match the split domains observed in the zebrafish cristae. Zebrafish aldh1a3, however, is detected in the anterior (utricular) macula, whereas the mouse ortholog is expressed both in the utricular and saccular sensory epithelia. More importantly, in zebrafish aldh1a2 is never expressed in the otocyst, instead expression is strong in cranial mesenchyme starting at $48 \mathrm{hpf}$ (not shown) and converges to regions of the periotic mesenchyme immediately medial to the otocyst (Fig. 4P). Thus aldhla3 is the only Raldh expressed within the zebrafish otocyst, while all three Raldhs are expressed in partially overlapping domains in the vestibular part of the mouse inner ear (Romand et al., 2004, 2006). An analysis in zebrafish of 

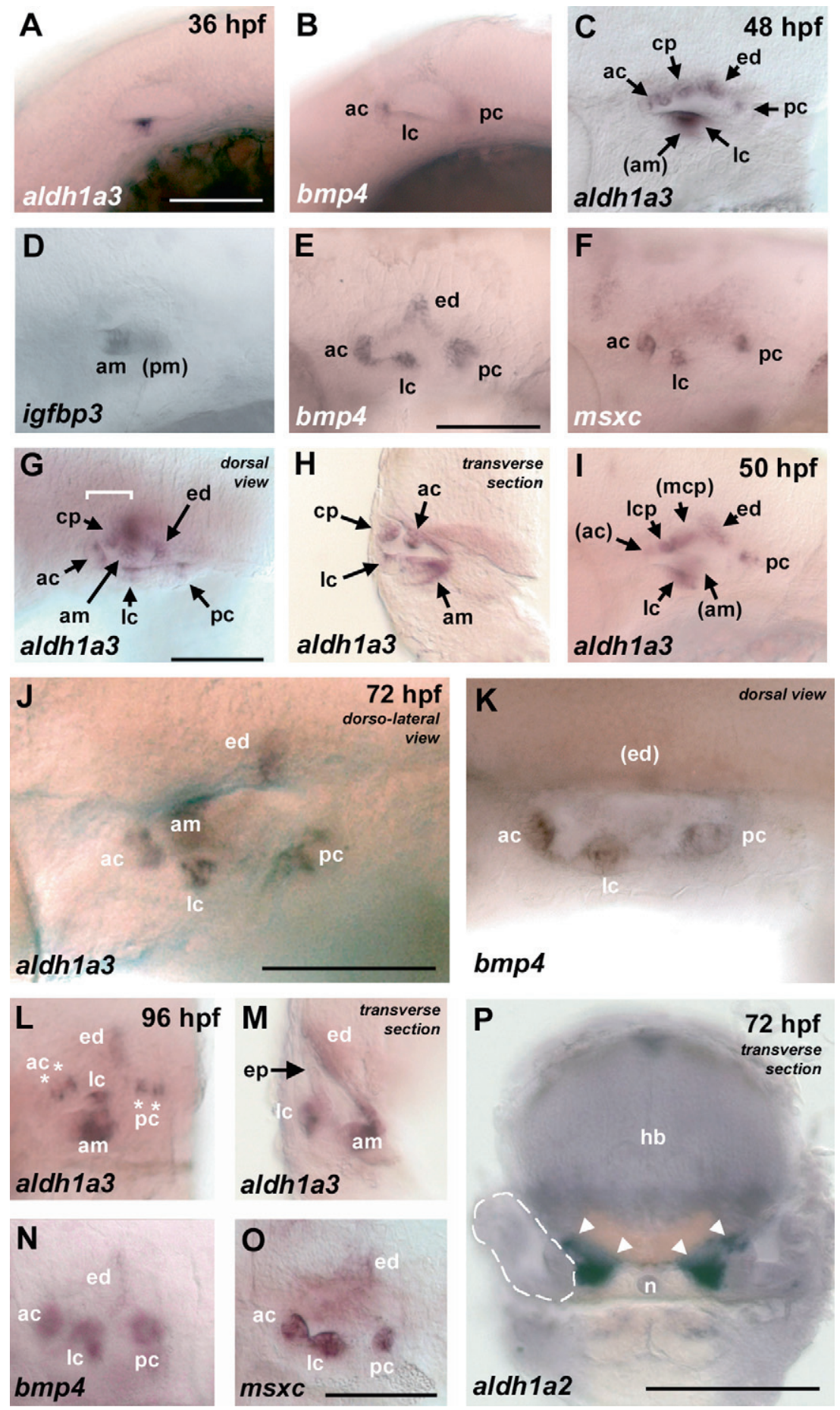

Fig. 4. Expression of aldh1a3 in the inner ear. aldhla3 expression (A, C, G J, L, M), in comparison to the expression of $b m p 4$ (B, E, K, N), $m s x c(\mathrm{~F}, \mathrm{O})$ igfbp3 (D) and aldh1a2 (P), was detected by whole mount in situ hybridisation in the zebrafish inner ear from 26 hpf to 96 hpf. Weak expression of aldh1a3 is visible in the ventral part of the otic vesicle at $26 \mathrm{hpf}$ and $36 \mathrm{hpf}$ (not shown and A). At $36 \mathrm{hpf}$ weak expression of $b m p 4$ in the otic vesicle marks the anterior (ac), lateral (lc) and posterior cristae (pc) (B). At $48 \mathrm{hpf}$ aldhla3 is detectable in the cristae, the endolymphatic duct (ed), the anterior macula (am), and the cranial epithelial projection $(\mathrm{cp})(\mathrm{C} ; \mathrm{G}$, dorsal view, bracket indicates extent of section in $\mathrm{H} ; \mathrm{H}$, transverse section through the otic capsule). Inner ear structures were identified by comparison to igfbp3, which marks the anterior and the posterior macula (pm, out of focus) (D), and to $b m p 4$ and $m s x c$, which show strong expression in the cristae, $b m p 4$ additionally in the endolymphatic duct ( $\mathrm{E}$ and $\mathrm{F}$ ). Expression in the cranial epithelial projection at $50 \mathrm{hpf}$ is visible on the lateral (lcp) and medial (mcp) surface of the projection (I, dorso lateral view with superficial focus on the lateral cranial projection). At $72 \mathrm{hpf}$, aldhla3 was detected in the anterior macula and in two opposing sectors within each of the cristae (J, dorso lateral view), while bmp4 appears to be more widely expressed in these organs (K, dorso lateral view). Like bmp4, aldhla3 expression persists in the endolymphatic duct (J, K). Expression of aldhla3, bmp 4 and $m s x c$ persists largely unchanged until $96 \mathrm{hpf}$, when the partition of the aldhla3 expression domains in the cristae becomes evident (asterisks in L; M, transverse section at the level of the lc; $\mathrm{N}$ and $\mathrm{O}$ ). Expression of aldhla2 is absent from the inner ear at least up until $72 \mathrm{hpf}$, but present in the periotic mesenchyme (arrowheads in P, transverse section, dashed lines outline the borders of the otocyst). All panels, unless otherwise indicated, are lateral views with anterior to the left. Parentheses indicate structures outside the focal plain. $\mathrm{n}$, notochord. Scale bars, $100 \mu \mathrm{m}$. 
RA signaling in inner ear development therefore should benefit from a comparable simple pattern of RA synthesis whose roles can be dissected through straightforward genetic and chemical manipulation.

\subsection{Conclusions}

Although zebrafish aldhla3 is expressed in many of the same structures as in the mouse embryo, we have observed a few notable differences: mouse Raldh3 expression was detected in the developing fronto-nasal surface ectoderm, where it has been shown to be required for olfactory organ patterning and morphogenesis of the nasal cavity ( $\mathrm{Li}$ et al., 2000; Mic et al., 2000; Dupe et al., 2003; Molotkov et al., 2006), but is absent from zebrafish olfactory tissues. A comparable Aldhla3 expression domain in the chick coordinates the development of the forebrain and frontonasal process (Schneider et al., 2001). Similarly, the rat expresses Raldh3 during kidney development (Marlier and Gilbert, 2004), while zebrafish show no expression in this organ. Finally, expression of Raldh 3 in $X$. laevis differs from that of the other vertebrates, as the gene is transcribed during gastrulation, while expression in later stages of development is similar to that in amniotes (Lupo et al., 2005). Lastly, the fact that zebrafish possess only two Raldh genes and the availability of mutants in aldhla2 (Begemann et al., 2001; Grandel et al., 2002) will have significant benefits for the dissection of RA signaling pathways during organ development. Our studies suggest that inner ear morphogenesis in particular, during which both genes are transcribed exclusively within and flanking the otic vesicle, is a paradigmatic case accessible to genetic manipulation of the RA pathway in zebrafish.

\section{Experimental procedures}

\subsection{Cloning of aldhla3}

The complete cDNA sequence of zebrafish aldhla3, previously called aldehyde dehydrogenase 6, is available from GenBank (Accession No: DQ300198; NM 001044745). To generate a probe for gene expression analysis by whole mount in situ hybridization, a fragment of 436 base pairs of aldhla 3 was amplified from $24 \mathrm{hpf}$ cDNA using the forward and reverse primers raldh3 for $22\left(5^{\prime}\right.$ gaatggggactctcgaaacacg $\left.3^{\prime}\right)$ and raldh3 rev456 ( $5^{\prime}$ cccatgaatettgtctgtccagc $\left.3^{\prime}\right)$, respectively, with the follow ing PCR conditions: $5 \mathrm{~min}$ at $94{ }^{\circ} \mathrm{C}, 35$ cycles of $30 \mathrm{~s}$ at $94{ }^{\circ} \mathrm{C}, 90 \mathrm{~s}$ at $54{ }^{\circ} \mathrm{C}$ and $90 \mathrm{~s}$ at $72{ }^{\circ} \mathrm{C}$, each, followed by an extension step of $7 \mathrm{~min}$ at $72^{\circ} \mathrm{C}$. The fragment was cloned into pCR II TOPO (Invitrogen), linear ized with BamHI and transcribed using T7 RNA Polymerase (Fermentas Life Sciences).

\subsection{Sequence and phylogenetic analyses}

We used the BLAST algorithm (Altschul et al., 1997) to screen the tel eost EST (GenBank) and genome databases (Ensembl; v42 Dec2006) for homologs of Aldhla gene family members. The list of identified sequences is available upon request from the authors. Protein sequence alignments were generated with Clustal X (Thompson et al., 1997), using the shortest common fragments of 120121 amino acids, homologous to positions 44
164 of zebrafish aldh1a2 (AAL26232). Based on this alignment, a Maxi mum Likelihood tree was calculated using PHYML (Guindon and Gasc uel, 2003) under the JTT $+\mathrm{I}+\mathrm{G}$ model $($ alpha $=2.02$, pinv $=0.22)$ as proposed by ProtTest (Abascal et al., 2005). Confidence in estimated rela tionships of ML tree topologies was evaluated by a bootstrap analysis with 500 replicates (Felsenstein, 1985) and Bayesian methods of phylogeny inference. Bayesian analyses were initiated with random seed trees and were run for 200,000 generations. The Markov chains were sampled at intervals of 100 generations with a burn in of 5000 trees. Bayesian phylo genetic analyses were conducted with MrBayes 3.1.1 (Huelsenbeck and Ronquist, 2001).

\subsection{Whole mount in situ hybridization}

Whole mount in situ hybridization was performed as previously described for aldh1a2 (Begemann et al., 2001), using cRNA probes labeled with digoxigenin UTP (Roche Applied Science). The following additional probes were used: msxc (Ekker et al., 1992), bmp4 (Mowbray et al., 2001) igfbp 3 (Li et al., 2005), and pomca (Herzog et al., 2003). Hybridization was detected with alkaline phosphate conjugated anti digoxigenin antibody followed by incubation with nitroblue tetrazolium and BCIP ( 5 bromo 4 chloro 3 indolyl phosphate). Stained embryos were examined with a Zeiss Axiophot microscope. Images were processed using Zeiss Axiovision and Adobe Photoshop software.

\section{Acknowledgements}

We thank Simone Hoegg for help with the phylogenetic analysis and Yann Gibert, Vincent Laudet, Yun Li and Matthias Hammerschmidt for providing cDNA clones. We also thank Rita Hellmann, Ingrid Mey and Elmar Spies for excellent technical assistance. This work was supported by the University of Konstanz and by a research grant from the Deutsche Forschungsgemeinschaft (BE 1902/51) to G.B.

\section{References}

Abascal, F., Zardoya, R., Posada, D., 2005. ProtTest: selection of best fit models of protein evolution. Bioinformatics 21, 21042105.

Adler, R., Belecky Adams, T.L., 2002. The role of bone morphogenetic proteins in the differentiation of the ventral optic cup. Development 129,31613171

Altschul, S.F., Madden, T.L., Schaffer, A.A., Zhang, J., Zhang, Z., Miller, W., Lipman, D.J., 1997. Gapped BLAST and PSI BLAST: a new generation of protein database search programs. Nucleic Acids Res. 25, 33893402 .

Begemann, G., Meyer, A., 2001. Hindbrain patterning revisited: timing and effects of retinoic acid signalling. BioEssays 23, 981986

Begemann, G., Schilling, T.F., Rauch, G.J., Geisler, R., Ingham, P.W., 2001. The zebrafish neckless mutation reveals a requirement for raldh2 in mesodermal signals that pattern the hindbrain. Development 128 , 30813094.

Berggren, K., Mccaffery, P., Drager, U., Forehand, C.J., 1999. Differential distribution of retinoic acid synthesis in the chicken embryo as determined by immunolocalization of the retinoic acid synthetic enzyme, RALDH 2. Dev. Biol. 210, 288304.

Canestro, C., Postlethwait, J.H., Gonzalez Duarte, R., Albalat, R., 2006. Is retinoic acid genetic machinery a chordate innovation? Evol. Dev. 8, 394406.

Chen, Y., Pollet, N., Niehrs, C., Pieler, T., 2001. Increased XRALDH2 activity has a posteriorizing effect on the central nervous system of Xenopus embryos. Mech. Dev. 101, 91103.

Duester, G., 2000. Families of retinoid dehydrogenases regulating vitamin A function. Eur. J. Biochem. 267, 43154324. 
Dupe, V., Matt, N., Garnier, J., Chambon, P., Mark, M., Ghyselinck, N., 2003. A newborn lethal defect due to inactivation of retinaldehyde dehydrogenase type 3 is prevented by maternal retinoic acid treatment. Proc. Natl. Acad. Sci. USA 100, 1403614041.

Ekker, M., Akimenko, M.A., Bremiller, R., Westerfield, M., 1992. Regional expression of three homeobox transcripts in the inner ear of zebrafish embryos. Neuron 9, 2735.

Felsenstein, J., 1985. Confidence limits on phylogenies: an approach using the bootstrap. Evolution Int. J. Org. Evolution 39, 783791.

Fujiwara, K., Maekawa, F., Kikuchi, M., Takigami, S., Yada, T., Yashiro, T., 2007. Expression of retinaldehyde dehydrogenase (RALDH)2 and RALDH3 but not RALDH1 in the developing anterior pituitary glands of rats. Cell Tissue Res. 328, 129135.

Grandel, H., Lun, K., Rauch, G.J., Rhinn, M., Piotrowski, T., Houart, C., Sordino, P., Kuchler, A.M., Schulte Merker, S., Geisler, R., Holder, N., Wilson, S.W., Brand, M., 2002. Retinoic acid signalling in the zebrafish embryo is necessary during pre segmentation stages to pattern the anterior posterior axis of the CNS and to induce a pectoral fin bud. Development 129, 28512865.

Grun, F., Hirose, Y., Kawauchi, S., Ogura, T., Umesono, K., 2000. Aldehyde dehydrogenase 6, a cytosolic retinaldehyde dehydrogenase prominently expressed in sensory neuroepithelia during development. J. Biol. Chem. 275, 4121041218

Guindon, S., Gascuel, O., 2003. A simple, fast, and accurate algorithm to estimate large phylogenies by maximum likelihood. Syst. Biol. 52, 696 704.

Haselbeck, R.J., Hoffmann, I., Duester, G., 1999. Distinct functions for Aldh1 and Raldh2 in the control of ligand production for embryonic retinoid signaling pathways. Dev. Genet. 25, 353364.

Herzog, W., Zeng, X., Lele, Z., Sonntag, C., Ting, J., Chang, C., Hammerschmidt, M., 2003. Adenohypophysis formation in the zebrafish and its dependence on sonic hedgehog. Dev. Biol. 254, 3649 .

Hubbard, T.J., Aken, B., Beal, K., Ballester, B., Caccamo, M., Chen, Y., Clarke, L., Coates, G., Cunningham, F., Cutts, T., Down, T., Dyer, S., Fitzgerald, S., Fernandez Banet, J., Graf, S., Haider, S., Hammond, M., Herrero, J., Holland, R., Howe, K., Howe, K., Johnson, N., Kahari, A., Keefe, D., Kokocinski, F., Kulesha, E., Lawson, D., Longden, I., Melsopp, C., Megy, K., Meidl, P., Ouverdin, B., Parker, A., Prlic, A., Rice, S., Rios, D., Schuster, M., Sealy, I., Severin, J., Slater, G., Smedley, D., Spudich, G., Trevanion, S., Vilella, A., Vogel, J., White, S., Wood, M., Cox, T., Curwen, V., Durbin, R., Fernandez Suarez, X.M., Flicek, P., Kasprzyk, A., Proctor, G., Searle, S., Smith, J., Ureta Vidal, A., Birney, E., 2007. Ensembl 2007. Nucleic Acids Res. 35, D610 D617.

Huelsenbeck, J.P., Ronquist, F., 2001. MRBAYES: bayesian inference of phylogenetic trees. Bioinformatics 17, 754755.

Li, H., Wagner, E., Mccaffery, P., Smith, D., Andreadis, A., Drager, U.C., 2000. A retinoic acid synthesizing enzyme in ventral retina and telencephalon of the embryonic mouse. Mech. Dev. 95, 283289.

Li, Y., Xiang, J., Duan, C., 2005. Insulin like growth factor binding protein 3 plays an important role in regulating pharyngeal skeleton and inner ear formation and differentiation. J. Biol. Chem. 280, 3613 3620 .

Lupo, G., Liu, Y., Qiu, R., Chandraratna, R.A., Barsacchi, G., He, R., Harris, W., 2005. Dorsoventral patterning of the Xenopus eye: a collaboration of Retinoid, Hedgehog and FGF receptor signaling. Development 132, 17371748.

Marlier, A., Gilbert, T., 2004. Expression of retinoic acid synthesizing and metabolizing enzymes during nephrogenesis in the rat. Gene Expr. Patterns 5, 179185.

Mccaffery, P., Tempst, P., Lara, G., Drager, U., 1991. Aldehyde dehydrogenase is a positional marker in the retina. Development 112,693702 .

Mic, F., Molotkov, A., Fan, X., Cuenca, A.E., Duester, G., 2000. RALDH3, a retinaldehyde dehydrogenase that generates retinoic acid, is expressed in the ventral retina, otic vesicle and olfactory pit during mouse development. Mech. Dev. 97, 227230.

Molotkov, A., Molotkova, N., Duester, G., 2006. Retinoic acid guides eye morphogenetic movements via paracrine signaling but is unnecessary for retinal dorsoventral patterning. Development 133, 19011910.

Mowbray, C., Hammerschmidt, M., Whitfield, T.T., 2001. Expression of BMP signalling pathway members in the developing zebrafish inner ear and lateral line. Mech. Dev. 108, 179184.

Niederreither, K., Mccaffery, P., Drager, U.C., Chambon, P., Dolle, P., 1997. Restricted expression and retinoic acid induced downregulation of the retinaldehyde dehydrogenase type 2 (RALDH 2) gene during mouse development. Mech. Dev. 62, 6778

Romand, R., Kondo, T., Fraulob, V., Petkovich, M., Dolle, P., Hashino, E., 2006. Dynamic expression of retinoic acid synthesizing and metabolizing enzymes in the developing mouse inner ear. J. Comp. Neurol. 496, 643654

Romand, R., Niederreither, K., Abu Abed, S., Petkovich, M., Fraulob, V., Hashino, E., Dolle, P., 2004. Complementary expression patterns of retinoid acid synthesizing and metabolizing enzymes in pre natal mouse inner ear structures. Gene Expr. Patterns 4, 123133.

Schneider, R., Hu, D., Rubenstein, J., Maden, M., Helms, J., 2001. Local retinoid signaling coordinates forebrain and facial morphogenesis by maintaining FGF8 and SHH. Development 128, 27552767.

Sophos, N.A., Vasiliou, V., 2003. Aldehyde dehydrogenase gene super family: the 2002 update. Chem. Biol. Interact., 522.

Suzuki, R., Shintani, T., Sakuta, H., Kato, A., Ohkawara, T., Osumi, N., Noda, M., 2000. Identification of RALDH 3, a novel retinaldehyde dehydrogenase, expressed in the ventral region of the retina. Mech. Dev. 98, 37 50.

Thompson, J.D., Gibson, T.J., Plewniak, F., Jeanmougin, F., Higgins, D.G., 1997. The Clustal X windows interface: flexible strategies for multiple sequence alignment aided by quality analysis tools. Nucleic Acids Res. 24, 48764882.

Waterman, R.E., Bell, D.H., 1984. Epithelial fusion during early semicir cular canal formation in the embryonic zebrafish, Brachydanio rerio. Anat. Rec. 210, 101114

Whitfield, T., Riley, B., Chiang, M.Y., Phillips, B., 2002. Development of the zebrafish inner ear. Dev. Dyn. 223, 427458. 